\title{
Alkali Therapy in Lactic Acidosis
}

\author{
Zeid Khitan, MD', Deepak Malhotra, MD PhD², \\ Dominic S Raj, MD³, Antonios H. Tzamaloukas, MD4, \\ Joseph I Shapiro, MD
}

ABSTRACT

This report attempts to frame the debate about clinical administration of sodium bicarbonate in the setting of lactic acidosis in terms of simple questions. Specifically, we address why we develop lactic acidosis in some circumstances, how acute lactic acidosis impairs cardiovascular function and why sodium bicarbonate may have deleterious effects which limit its utility. We also attempt to explore treatment alternatives to sodium bicarbonate.
Author affiliations are listed at the end of this article.

Correspondence to: Joseph I. Shapiro, MD Marshall University Joan C. Edwards School of Medicine shapiroj@marshall.edu

\section{KEYWORDS}

lactic acidosis, sodium bicarbonate, carbicarb

\section{INTRODUCTION}

The treatment of lactic acidosis remains controversial. Although many in vitro and animal studies were performed over the past 40 years, there is still a dearth of clinical data addressing simple questions such as whether sodium bicarbonate therapy is deleterious or beneficial or whether alternative buffers such as tris (hydroxymethyl)aminomethane (THAM) or a combination of sodium bicarbonate with disodium carbonate (Carbicarb) offer advantages to patients. In this report we will attempt to highlight the key issues that may be useful in the design of subsequent clinical treatments and studies. To this end, we plan to frame and answer some very simple questions.

\section{WHY DO WE GENERATE LACTIC ACIDOSIS?}

The end product of anaerobic glycolysis is pyruvate, which can be metabolized to carbon dioxide by the energy efficient Krebs cycle in the mitochondria. Alternatively, pyruvate can be metabolized by an energy inefficient pathway by the enzyme lactate dehydrogenase to lactate:

$$
\left(\text { Pyruvate }+\mathrm{NADH}+\mathrm{H}^{+}<->\text {lactate }+\mathrm{NAD}^{+}\right)
$$

Lactic acidosis, one consequence of the shock state is associated with cellular dysfunction and is a predictor of mortality and morbidity. ${ }^{1-3}$ Together with diabetic ketoacidosis, it accounts for approximately $85 \%$ of the cases of acute severe metabolic acidosis. ${ }^{4}$ The major causes of lactic acidosis are typically divided into disorders associated with tissue hypoxia (type A) and disorders in which tissue hypoxia is absent (type B). Cardiogenic or hypovolemic shock, severe heart failure, severe trauma and sepsis are the most common causes of type A lactic acidosis. ${ }^{5}$ Normally, approximately $1400 \mathrm{mmol}$ of lactic acid are produced daily, primarily by skeletal muscle and gut. The production of lactic acid is balanced by the metabolism of an equivalent amount of the compound in the liver, which constitutes the Cori cycle. Other tissues including the kidneys are capable of metabolizing lactate as well. In humans, the kidneys contribute approximately $10-20 \%$ of lactate removal.6 On the other hand, tissue hypoxia results in excessive lactate production which can increase 
under pathological conditions nearly 100 fold. $^{6}$

Lactate removal takes place via its oxidation to pyruvate by lactate dehydrogenase. Pyruvate may be either oxidized to carbon dioxide producing energy or transformed into glucose through gluconeogenesis. Pyruvate oxidation requires oxygen supply and the cooperation of pyruvate dehydrogenase, the tricarboxylic acid cycle, and the mitochondrial respiratory chain. Congenital or acquired deficiencies in gluconeogenesis including tissue hypoxia may induce lactate accumulation. ${ }^{7}$ Impaired mitochondrial oxidative function, as occurs in hypoxic states, leads to accumulation of pyruvate in the cytosol and thus to increased lactate production. The accumulation of pyruvate in the hypoxic state reflects both overproduction of pyruvate and reduced utilization of pyruvate through its two pathways, the oxidative decarboxylation to acetyl-coenzyme $A$ (acetyl-CoA) and gluconeogenesis. ${ }^{8}$

\section{IS THE DEVELOPMENT OF ACIDOSIS A “BAD” THING?}

Clearly there are some "good" things about acidosis. On a tissue level, a moderate degree of acidosis allows for greater delivery of oxygen, the shortage of which often underlies the basic pathophysiology of lactic acidosis (see above). Acidosis also appears to decrease the ongoing rate of lactic-acid generation (or ketoacid generation). This negative feedback attenuates the net degree of acidemia. ${ }^{9}$

However, if we examine the effect of acidosis on the heart and the vascular system, one must conclude that it is generally deleterious. In cardiac cells, the drop in intracellular $\mathrm{pH}$ is known to have deleterious effects on myocardial contractile function. ${ }^{9-11}$ This has been clearly shown in the isolated perfused rat heart. ${ }^{12}$ Schotola, et al studied the effect of incremental dose of the beta agonist isoproterenol on human ventricular trabeculae at $\mathrm{pH} 7.20$ and 7.40. They observed a reduction in cardiac contractility and rightward shift of the isoproterenol dose response curve at $\mathrm{pH} 7.20 . .^{13,14}$ In intact animals, compensatory mechanisms related to the neuroendocrine response initially maintain cardiac output, but ultimately cardiac output falls with severe acidosis ${ }^{15,16}$ as we discuss below.

Several cellular and functional processes have been implicated in the pathogenesis of cardiac contractile dysfunction in severe acidemia. These include impairment of energy production, ${ }^{15,17}$ disturbances in intracellular calcium transport and cycling, ${ }^{18-24}$ and impairment of actin-myosin crossbridge cycling by inorganic phosphate $(\mathrm{Pi})$ and $\mathrm{H} \otimes$ accumulation. ${ }^{25}$ In myocardial cells metabolic acidosis results in increased energy demand that exceeds energy production. ${ }^{15}$ This discrepancy between demand and production of energy is evidenced by decreases in creatinine phosphate $(\mathrm{PCr})$ and reciprocal increases in inorganic phosphate $(\mathrm{Pi})$ beyond what would be expected from the calculated increases in $[\mathrm{H}+] .{ }^{16}$ The decrease in energy production in the isolated perfused heart appears to be the result of inhibition of the mitochondrial oxidative phosphorylation more than direct effects on glycolysis through allosteric effects on phosphofructokinase. ${ }^{17}$

Intracellular $\mathrm{pH}$ also has a considerable impact on the amplitude of the systolic calcium transient and subsequent excitation-contraction coupling pathway. The net impact of intracellular acidosis is an increase in the calcium transient amplitude due to increased sarcoplasmic reticulum calcium content which subsequently affects the excitationcontraction coupling pathway. It was also demonstrated that global acidosis or ischemia modifies Cai2+ cycling in myocytes causing a rise in the diastolic Cai2+ and prolongation of the cellular calcium transient characterizing a potential proarrhythmic state. ${ }^{26}$

As mentioned earlier, it is apparent that the sympathoadrenal system constitutes an important aspect of the heart's response to acidosis. ${ }^{27}$ Increased release of catecholamines in response to the acidic environment from cardiac nerve endings and adrenal medulla was observed but myocardial responsiveness to catecholamines was found to be altered along with markedly enhanced vagal stimulation. ${ }^{28-32}$ Mitchell et al demonstrated that in moderate acidosis $(\mathrm{pH}>7.2)$, there is actually an increase in the maximal rate of left ventricular pressure $(\max \mathrm{dp} / \mathrm{dt})$ and stroke volume related to 
the increased catecholamine levels, but with severe acidosis, the contractile state of the left ventricle is significantly depressed. ${ }^{27}$ Teplinsky and colleagues showed that experimental lactic acidosis caused a $40 \%$ reduction in stroke volume without reducing venous return in animals suggesting impaired myocardial contractility. ${ }^{33}$ Davies demonstrated that human beta 2-adrenergic receptors were altered in an in vitro model of lactic acidosis accompanied by resistance to the inotropic and vasoconstrictive effects of infused catecholamines. ${ }^{34}$ In another study by Kellum and colleagues, moderate and severe acidosis caused hypotension in animals without affecting plasma levels of inflammatory markers. ${ }^{35}$ Conduction abnormalities which predispose to ventricular arrhythmias are often found in animal models of metabolic acidosis. This finding can explain the ventricular irritability observed during myocardial ischemia. ${ }^{36}$

\section{IF ACIDOSIS IS “BAD," WHY ISN'T THE ADMINISTRATION OF SODIUM BICARBONATE "GOOD?"}

It is very clear that therapy directed to the specific cause of the acidosis is rational. Clinical outcomes are in fact quite good when such intervention effectively normalizes the production of acid as is the case with diabetic ketoacidosis and some cases of toxic alcohol ingestion where the process of organic acid production can be stopped. On the other hand, conditions presenting with type A lactic acidosis and associated circulatory disturbances and tissue hypoxia as in sepsis or cardiac arrest seem to require addressing the acidosis directly. In fact, given the potential deleterious effects of severe acidosis, some experts recommend intravenous sodium bicarbonate therapy although its value in reducing mortality or improving hemodynamics remains unproven. ${ }^{5}$

Questioning the utility of bicarbonate therapy began in the late 1970s with the observation in experimental lactic acidosis that bicarbonate therapy worsened outcomes. In animal models of lactic acidosis, administration of $\mathrm{NaHCO} 3$ increased lactate production by the splanchnic bed. ${ }^{37}$ Graf et $\mathrm{a}^{38}$ compared the effect $\mathrm{NaHCO} 3$ therapy in dogs with hypoxic lactic acidosis with the effects of sodium chloride or no therapy. Treatment with $\mathrm{NaHCO} 3$ was associated with decreases in cardiac output and blood pressure compared with the other two groups. Moreover and despite the infusion of $\mathrm{NaHCO} 3$, both arterial $\mathrm{pH}$ and bicarbonate concentration decreased by a similar amount in all three groups of dogs. This was postulated to result primarily from a paradoxical intracellular acidosis resulting from the rapid equilibrium of $\mathrm{CO} 2$ across the cell membrane and the delayed equilibration of bicarbonate. ${ }^{39}$ Other possible adverse effects of sodium bicarbonate therapy include hypertonicity and delayed metabolic alkalosis, ${ }^{32,40}$ but the paradoxical intracellular acidosis is probably the most important. Graf and colleagues measured intracellular liver $\mathrm{pH}$ with $\mathrm{DMO}$ distribution and found bicarbonate actually lowered this value in their animal model.38 This has been confirmed using other methods of intracellular $\mathrm{pH}$ determination. 12,15,16,41 To fully understand this, we can look at what happens when the bicarbonate

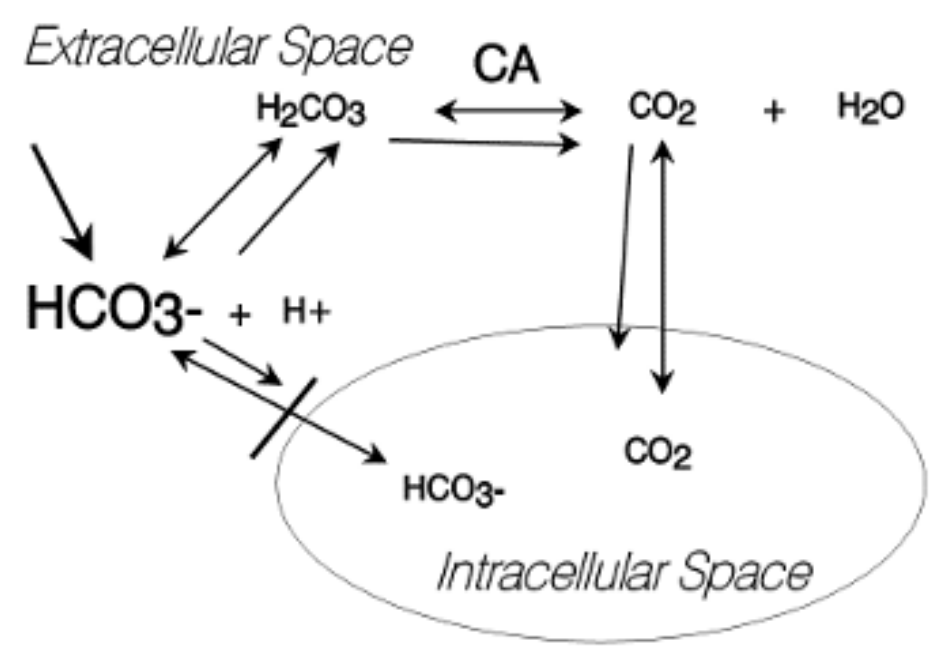

FIGURE 1: Schematic illustrating effects of sodium bicarbonate ( $\mathrm{HCO} 3-)$ administration into an acidotic milleiu. Other abbreviations: $\mathrm{H}+$ - protons, $\mathrm{H} 2 \mathrm{CO} 3$ carbonic acid, $\mathrm{CO} 2-$ carbon dioxide, CA - carbonic anhydrase. 
buffer system is open vs. closed.

In an open system (i.e., when tissue perfusion and pulmonary ventilation is adequate), $\mathrm{CO} 2$ tension is controlled by the brain stem through respiratory drive and the $\mathrm{CO} 2$ which is generated from oxidative metabolism of carbon containing organic compounds and the dehydration of $\mathrm{H}_{2} \mathrm{CO} 3$ by carbonic anhydrase (figure 1 ) is eliminated by the lungs. This has been shown in both experimental animals $\mathrm{s}^{42}$ and humans ${ }^{43}$. Such a system can be modelled experimentally using an instrument called a tonometer where the $\mathrm{CO} 2$ tension can be held constant. ${ }^{44}$ However, when tissue perfusion and/or pulmonary ventilation are compromised as occurs during circulatory shock, the clinical scenario more closely approximates a closed system. A simple model for a closed system is a glass syringe with a gas tight rubber stopper. ${ }^{45}$

Kimmoun et $\mathrm{al}^{46}$ investigated the cardiovascular and metabolic effects of an adaptive sodium bicarbonate therapy, including ventilation of $\mathrm{CO} 2$ increase with hyperventilation and ionized calcium decrease with calcium administration. Their strategy normalized extra- and intracellular $\mathrm{pH}$, improved cardiac elastance and improved aortic and mesenteric vasoactivity compared with controls. Small studies have shown promising results when high dose bicarbonate was administered via continuous venovenous hemofiltration to treat acidosis and renal failure. ${ }^{47,48}$ The harmful effect of bicarbonateinduced widespread intracellular acidosis on cellular and metabolic function, particularly the heart, suggests that alternative buffers compatible to bicarbonate but without the $\mathrm{CO} 2$ generating potential might offer clinical advantages.

\section{ALTERNATIVE BUFFERS}

In an effort to overcome the side effects of sodium bicarbonate, other alkali therapies have been developed. THAM, (tris-hydroxymethylaminomethan), dichloroacetate and Carbicarb constitute the most prominent molecules in this context. THAM was first introduced into clinical practice in $1959.4930 \%$ of this compound exists in the nonionized form where it can penetrate cells and thereby raise the intracellular $\mathrm{pH}$ by buffering protons by virtue of the ammonia moiety. ${ }^{40}$ In experimental studies, THAM was found to have a comparable buffering capacity to bicarbonate but without intracellular acidosis..$^{50}$ Moreover, THAM was found to have a favorable effect on myocardial contractility when used in dogs with lactic acidosis51 as well as in perfused isolated heart model during metabolic acidosis ${ }^{52}(\mathrm{pH}=7.0)$.

Clinical trials assessing THAM in patients with lactic acidosis are limited. Hoste and colleagues showed that administration of THAM to patients in ICU with mild metabolic acidosis was as effective as sodium bicarbonate.53 Further studies looking at outcome and cardiovascular function are needed to examine the use of THAM in the treatment of acute metabolic acidosis. THAM has considerable side effect profile including hepatic failure and hyperkalemia. Moreover, THAM is excreted by the kidney in its protonated form. Therefore, its usefulness would appear to be limited to acidosis in the presence of significant renal failure. ${ }^{40}$

Dichloroacetate (DCA) is another investigational drug that has been studied in lactic acidosis. DCA exerts multiple effects on pathways of intermediate metabolism resulting in stimulation of peripheral glucose utilization and inhibition of gluconeogenesis. ${ }^{54}$ In lactic acidosis, DCA is believed to facilitate the oxidation of lactate by stimulating the activity of pyruvate dehydrogenase. In healthy volunteers during incremental exercise, DCA resulted in the reduction of blood lactate accumulation accompanied by reduction in pulmonary $\mathrm{CO} 2$ output without enhancing exercise tolerance. ${ }^{55}$ However, in a randomized controlled trial in patients with lactic acidosis, DCA resulted in statistically significant but clinically unimportant changes in arterial-blood lactate concentrations and $\mathrm{pH}$ and fails to alter either hemodynamics or survival. ${ }^{56}$ DCA is not currently available in the United States for clinical use.

Carbicarb, a mixture of equimolar quantities of sodium bicarbonate and sodium carbonate was first formulated in 1983 by Filley and Kindig..$^{57}$ Sodium carbonate in the mixture reacts with carbonic acid $(\mathrm{H} 2 \mathrm{CO} 3)$ to generate bicarbonate via the following reaction. ${ }^{45,57}$ 


$$
\mathrm{CO}^{-2}+\mathrm{H}_{2} \mathrm{CO} 3<->2 \mathrm{HCO}^{-}
$$

Thus, the carbonate component of Carbicarb consumes $\mathrm{CO}_{2}$ while the $\mathrm{HCO}^{-}$component and the newly generated $\mathrm{HCO}^{-}$will form $\mathrm{CO} 2$ when protons are buffered. At the cellular level, systemic [administration of] Carbicarb to treat severe acidosis resulted in systemic alkalinization without major changes in $\mathrm{PaCO} 2$ and intracellular $\mathrm{pH}$ in hepatocytes ${ }^{16}$, isolated heart ${ }^{12,58,59}$ and brain cells 41 compared with $\mathrm{NaHCO} 3$ therapy which resulted in paradoxical intracellular acidosis. In animals [with lactic acidosis], Carbicarb was found to be superior to $\mathrm{NaHCO} 3$ with improved tissue $\mathrm{pH}$, lactate production and cardiac hemodynamics.60 In healthy volunteers, Carbicarb was associated with transient decrease in $\mathrm{PaCO} 2$ compared with sodium bicarbonate. ${ }^{43}$

In a study of 36 patients undergoing surgery who developed mild acidosis, Carbicarb was found to be safe and comparable to NaHCO3. ${ }^{61}$ Controlled studies of the impact of Carbicarb in patients with severe acidosis have not been reported and the drug is not currently available in the United States.

Carbicarb is an efficient buffer that does not cause intracellular acidosis. It has the potential for treating acute acidosis without impairing cellular and cardiac function. Each molecule of $\mathrm{CO}^{-2}$ will effectively eliminate one hydrogen ion in the blood, thereby directly lowering the proton concentration and raising $\mathrm{pH}$. In addition, $\mathrm{HCO}^{3}$, the product of $\mathrm{CO}^{-2}$ buffering is the main component of the sodium bicarbonate solution that is safe in humans and has excellent cellular permeability. On the other hand, Carbicarb can be damaging to the adjacent tissues after injection due to its hypertonic nature and the high level of alkalinity. ${ }^{62}$ Moreover, stability problems with the mixture and the proposed delivery syringe have slowed its entry into the clinic. Specifically, the extremely high $\mathrm{pH}$ of Carbicarb appears to degrade the rubber stoppers which can safely be used to seal bicarbonate ampules (unpublished observations).

\section{SIMULATIONS OF DIFFERENT COMBINATIONS OF BICARBONATE AND CARBONATE}

As mentioned above, Carbicarb, like THAM, was developed with the aim of avoiding "paradoxical" intracellular acidosis. To examine what changes in $\mathrm{PaCO} 2$ and $\mathrm{pH}$ might be anticipated, we performed the following simulations guided by the observed responses seen with closed and open systems. ${ }^{45}$ Specifically, we found in the past that when bicarbonate was added to a closed system, we observed very little change in $\mathrm{pH}$ but rather marked increases in PaCO2. In contrast, the addition of carbonate to a closed system resulted in the rapid consumption of $\mathrm{CO} 2$ as new $\mathrm{HCO} 3$ was generated. Using these principles and the known values for $\mathrm{CO} 2$ solubility and the equilibrium constant for the $\mathrm{H} 2 \mathrm{CO} 3$ - HCO3- system, simulations were performed using the programming language MatlabTM (R2014a, the Mathworks, Inc.,) using code detailed in Appendix 1.

We first examined the effects of $\mathrm{NaHCO}_{3}$ addition in an "open" system where $\mathrm{PaCO} 2$ was maintained at 40 torr. Bicarbonate caused no changes in $\mathrm{PaCO} 2$ (by definition, figure 2a) and increase in final $\mathrm{pH}$ in proportion to the change in $\mathrm{HCO}^{-}$(figure 2b). In such a system, addition of carbonate was twice as potent as bicarbonate as the reaction $\mathrm{CO}^{-2}+\mathrm{CO} 2$ $\longrightarrow 2 \mathrm{HCO}^{-}$predicted, but no qualitative differences were noted (data not shown). In contrast, when bicarbonate was added to a closed system, increases in $\mathrm{PaCO} 2$ were seen in proportion to the initial $[\mathrm{H}+]$ with essentially no change in $\mathrm{pH}$ as we observed in the aforementioned experimental publication ${ }^{45}$, (figures $2 \mathrm{c}$ and $2 \mathrm{~d}$, respectively). Disodium carbonate however was a very effective alkalinizing agent over a wide range of $\mathrm{pH}$ values (figure 3 panel a and b). When we looked at varying the proportion of carbonate to bicarbonate in a mixture, it appeared that $\mathrm{CO} 2$ neutrality was achieved at relatively low proportions of carbonate, especially when the initial $\mathrm{PaCO} 2$ was high (figure 4, panels a and b).

\section{CONCLUSIONS}

It is very clear that, while cardiovascular function is embarrassed by acute lactic acidosis, treatment with sodium bicarbonate may have deleterious effects that appear largely related to its propensity to generate $\mathrm{CO} 2$ in a closed system. As there is no accepted methodology for assessing whether the patient's milieu is more closely approximated by 


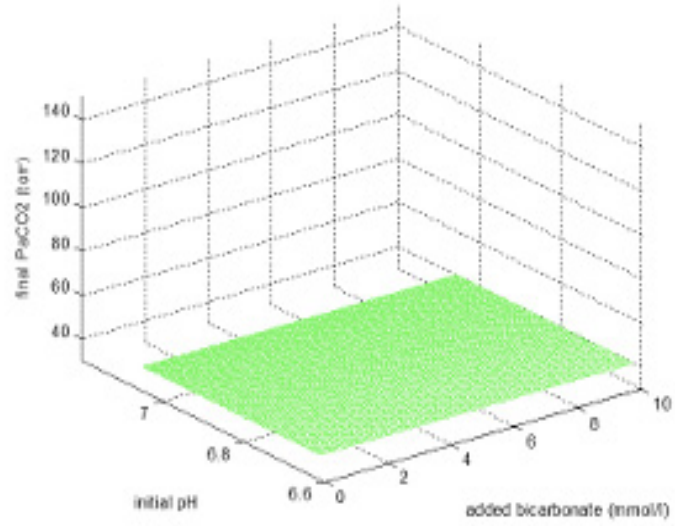

FIGURE 2A

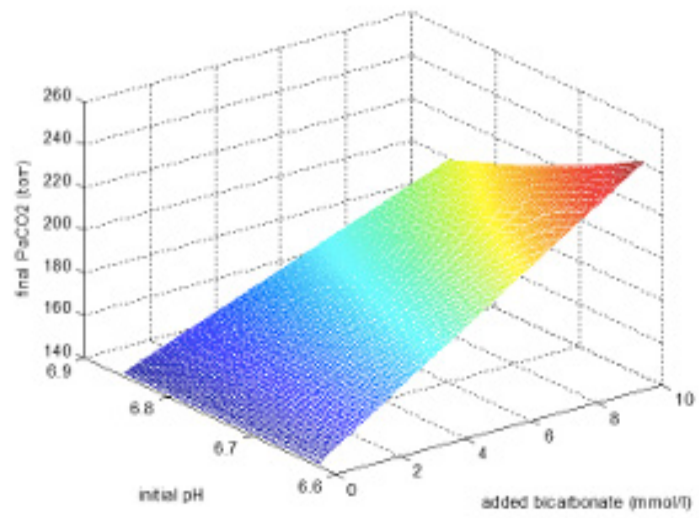

FIGURE 2C

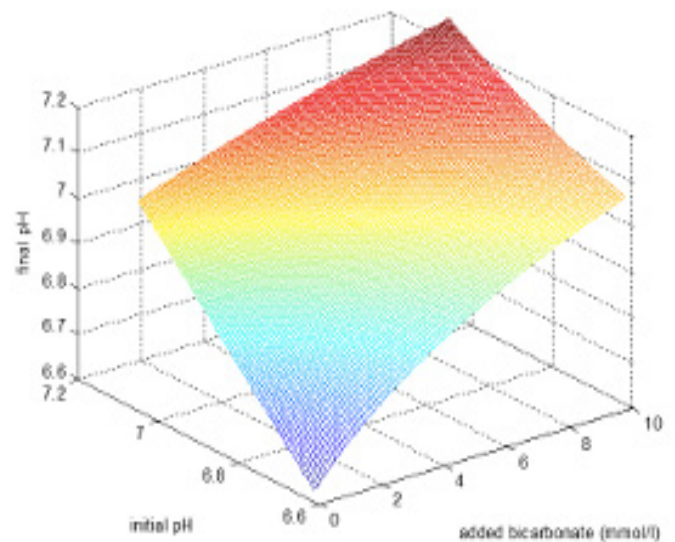

FIGURE 2B

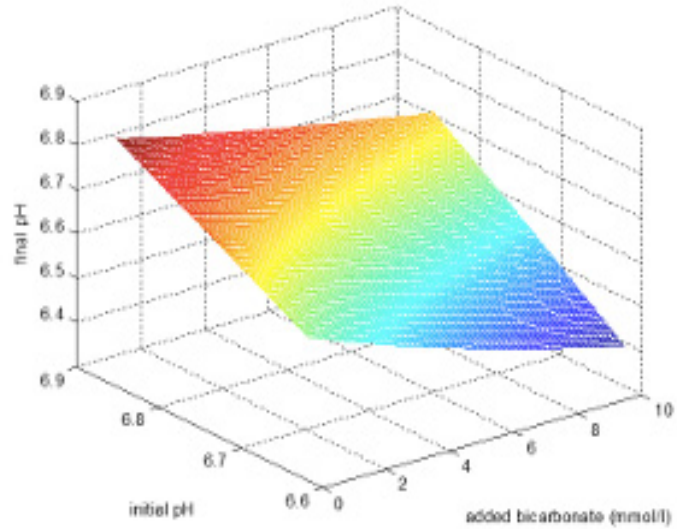

FIGURE 2D

FIGURE 2: Simulated changes in $\mathrm{PaCO} 2$ and $\mathrm{pH}$ in open and closed system following addition of HCO3- $(0-10 \mathrm{meq} / \mathrm{l})$ with starting PaCO2 of 40 torr and initial pH (6.4 to 7.0). Panels $2 \mathrm{a}$ and $2 \mathrm{~b}$ show $\mathrm{PaCO} 2$ and $\mathrm{pH}$ (respectively) in open system and Panels $2 \mathrm{c}$ and $2 \mathrm{~d}$ show PaCO2 and pH (respectively) in closed system. 


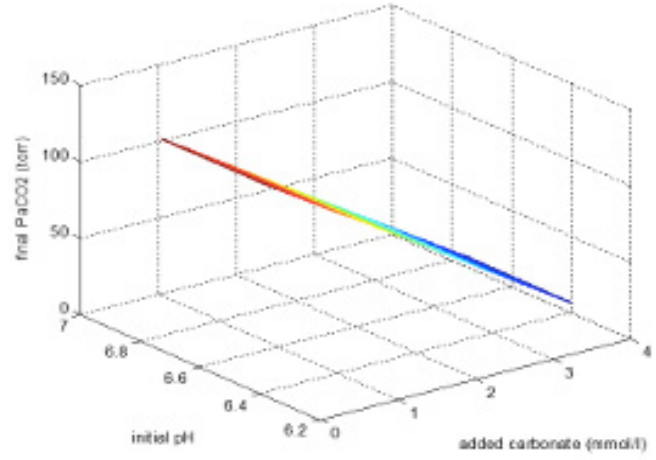

FIGURE 3A

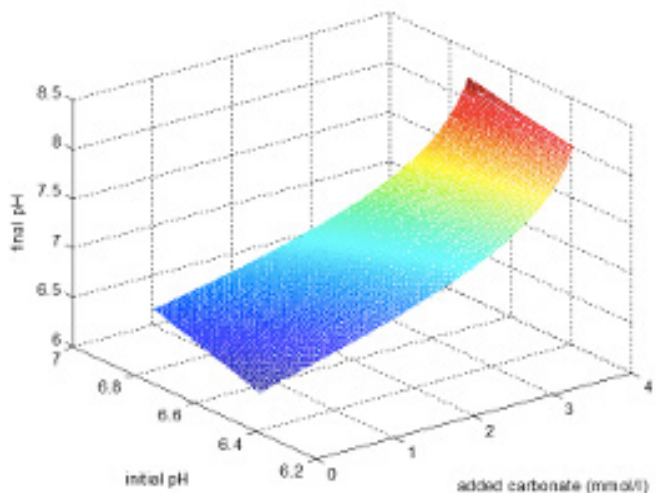

FIGURE 3B

FIGURE 3: Simulated changes in PaCO2 (Panel 3a) and pH (Panel 3b) in a closed system following addition of disodium carbonate $(0-4 \mathrm{mmol} / \mathrm{l})$ with initial $\mathrm{pH}$ varied between 6.4 and 7 with initial $\mathrm{PaCO} 2$ of 100 torr.

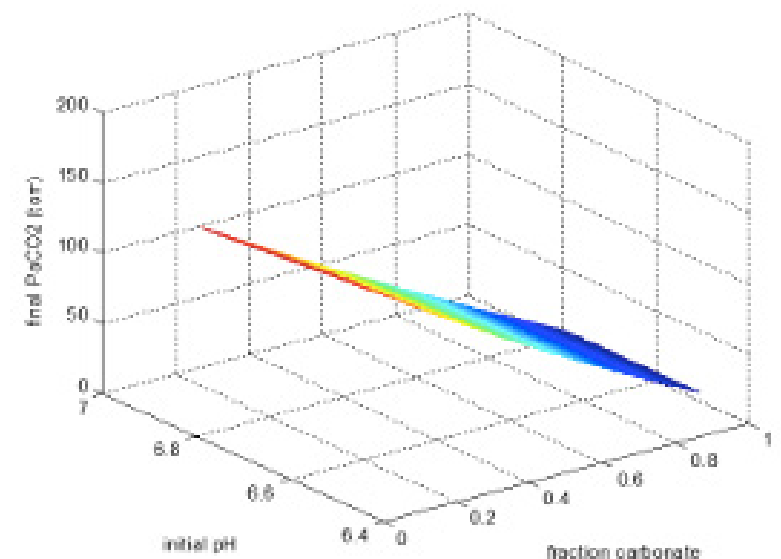

FIGURE 4A

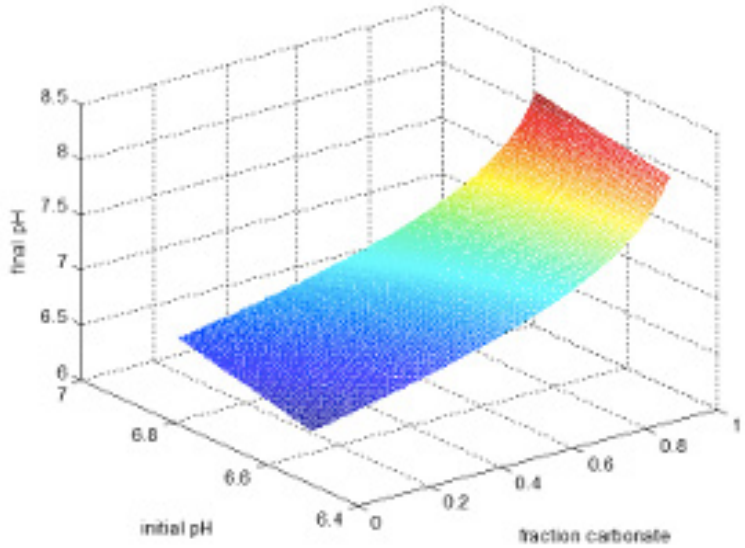

FIGURE 4B

FIGURE 4: Simulated changes in PaCO2 (Panel 4a) and pH (Panel 4b) in a closed system following addition of a mixture of disodium carbonate and sodium bicarbonate (total $2 \mathrm{mmol} / \mathrm{l}$ of carbonate + bicarbonate) with initial $\mathrm{pH}$ varied between 6.4 and 7 with initial $\mathrm{PaCO} 2$ of 100 torr. 
a closed or an open system, it is very difficult to advise physicians whether or how to administer sodium bicarbonate in the clinical setting of lactic acidosis. Although some experimental buffers have been developed which appear promising, further clinical proof is necessary before their use can be advocated. Our simulations showed that solutions containing carbonate to bicarb ratios less than 1:1 might be useful In treating lactic acidosis. It needs to be examined if these solutions with different ratios will differ from carbicarb in terms of stability and administration issues."

\section{APPENDIX 1: MATLABTM CODE}

\%bicarbonate addition simulation open

for $i=1: 100$

$\mathrm{HCO} 3 \mathrm{~m}(\mathrm{i})=4+\mathrm{i} / 10$;

$\mathrm{aHCO} 3(\mathrm{i})=\mathrm{i} / 10$;

$\mathrm{pCO} 20=40$;

end

for $i=1: 100$

for $j=1: 100$

$\mathrm{pH}(\mathrm{i}, \mathrm{j})=6.1+\log 10(\mathrm{HCO} 3 \mathrm{~m}(\mathrm{i})+\mathrm{aHCO} 3(\mathrm{j})) / 1.2 ;$ $\mathrm{pCO} 2(\mathrm{i}, \mathrm{j})=40$;

end

end

$\operatorname{mesh}(\mathrm{aHCO}, \mathrm{pH}(:, 1), \mathrm{pH})$

axis([0 106.67 .26 .67 .2$])$

xlabel('added bicarbonate $(\mathrm{mmol} / \mathrm{l})$ ')

ylabel('initial $\mathrm{pH}^{\prime}$ )

zlabel('final $\mathrm{pH}$ ')

figure

mesh(aHCO3,pH(:,1),pCO2)

axis([0 106.67 .230150$])$

xlabel('added bicarbonate $(\mathrm{mmol} / \mathrm{l})$ ')

ylabel('initial $\mathrm{pH}^{\prime}$ )

zlabel('final PaCO2 (torr)')

\%bicarbonate addition simulation open

for $i=1: 100$

$\mathrm{HCO} 3 \mathrm{~m}(\mathrm{i})=14+\mathrm{i} / 10$;

$\operatorname{aHCO} 3(\mathrm{i})=\mathrm{i} / 10$;

pCO20=140;

$\mathrm{pH}(\mathrm{i}, 1)=6.1+\log 10\left(\mathrm{HCO} 3 \mathrm{~m}(\mathrm{i}) /\left(\mathrm{pCO} 20^{*} 0.03\right)\right)$;

end

for $i=1: 100$

for $j=1: 100$

$\mathrm{pCO} 2(\mathrm{i}, \mathrm{j})=\left((\mathrm{HCO} 3 \mathrm{~m}(\mathrm{i})+\mathrm{aHCO} 3(\mathrm{j}))^{*} 10^{\wedge}-\mathrm{pH}(\mathrm{i}, 1)\right) /$
$(0.03 * 10 \wedge(-6.1))$;

$\mathrm{pH}(\mathrm{i}, \mathrm{j})=6.1+\log 10(\mathrm{HCO} 3 \mathrm{~m}(\mathrm{i}) /(0.03 * \mathrm{pCO} 2(\mathrm{i}, \mathrm{j})))$; end

end

$\operatorname{mesh}(\mathrm{aHCO}, \mathrm{pH}(:, 1), \mathrm{pH})$

\%axis([0 106.67 .26 .67 .2$])$

xlabel('added bicarbonate $(\mathrm{mmol} / \mathrm{l})$ ')

ylabel('initial $\mathrm{pH}$ ')

zlabel('final $\mathrm{pH}$ ')

figure

mesh(aHCO3,pH(:,1),pCO2)

\%axis([0 106.67 .230150$])$

xlabel('added bicarbonate $\left.(\mathrm{mmol} / \mathrm{l})^{\prime}\right)$

ylabel('initial $\mathrm{pH}$ ')

zlabel('final PaCO2 (torr)')

$\%$ carbonate addition simulation closed

pCO20=140;

keq $=1.2 /((40 \mathrm{e}-6) * 24)$;

for $i=1: 100$

$\mathrm{HCO} 3 \mathrm{~m}(\mathrm{i})=8+\mathrm{i} / 10$;

$\mathrm{CN}(\mathrm{i})=\mathrm{i} / 25$;

end

for $i=1: 100$

for $j=1: 100$

$\mathrm{x}=\mathrm{pCO} 20^{*} 0.03$;

$\mathrm{a}=\mathrm{HCO} 3 \mathrm{~m}(\mathrm{i})+2{ }^{*} \mathrm{CN}(\mathrm{j})$;

$z=6.1+\log 10(a / x)$;

$\mathrm{x}=\mathrm{x}-\mathrm{CN}(\mathrm{j})$;

$z=6.1+\log 10(a / x)$;

$\mathrm{x}=1000^{*} \mathrm{a}^{*} \mathrm{keq}^{*} 10^{\wedge}-\mathrm{z} ;$

$z=6.1+\log 10(a / x)$;

$\mathrm{x}=1000^{*} \mathrm{a}^{*} \mathrm{keq}^{*} 10^{\wedge}-\mathrm{z}$;

$\mathrm{pH}(\mathrm{i}, \mathrm{j})=\mathrm{z}$;

$P C O 2(i, j)=x / 0.03$;

end

end

$\operatorname{mesh}(\mathrm{CN}, \mathrm{pH}(:, 1), \mathrm{pH})$

\%axis([0 1.06 .67 .26 .6 8.0] $)$

xlabel('added carbonate $(\mathrm{mmol} / \mathrm{l}$ )')

ylabel('initial $\mathrm{pH}^{\prime}$ )

zlabel('final $\mathrm{pH}$ ')

figure

mesh(CN,pH(:,1),PCO2)

\%axis([0 1.06 .67 .2040$]$ )

xlabel('added carbonate $(\mathrm{mmol} / \mathrm{l})$ ')

ylabel('initial $\mathrm{pH}$ ') 


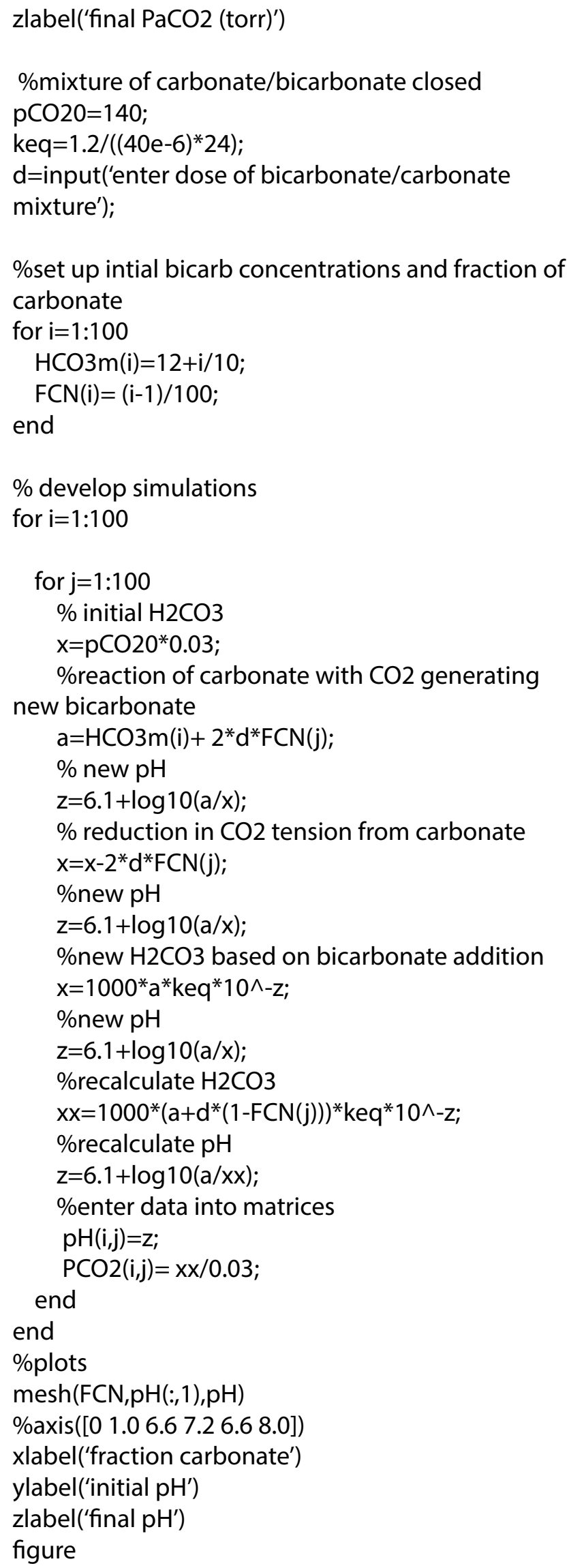

$\operatorname{mesh}(\mathrm{FCN}, \mathrm{pH}(:, 1), \mathrm{PCO} 2)$

$\%$ axis([0 1.06 .67 .2040$])$

xlabel('fraction carbonate')

ylabel('initial $\mathrm{pH}$ ')

zlabel('final PaCO2 (torr)')

\section{AUTHOR AFFILIATIONS}

1. Department of Medicine, Marshall University Joan C. Edwards School of Medicine

2. Department of Medicine, University of Toledo School of Medicine

3. Department of Medicine, George Washington University School of Medicine

4. Department of Medicine, University of New Mexico School of Medicine.

\section{REFERENCES}

1. Jung B, Rimmele T, Le Goff C, Chanques G, Corne $P$, Jonquet $O$, Muller $L$, Lefrant JY, Guervilly $C$, Papazian L, Allaouchiche B and Jaber S. Severe metabolic or mixed acidemia on intensive care unit admission: incidence, prognosis and administration of buffer therapy. A prospective, multiple-center study. Crit Care. 2011;15:R238.

2. Kraut JA and Madias NE. Metabolic acidosis: pathophysiology, diagnosis and management. Nat Rev Nephrol. 2010;6:274-85.

3. Lee SW, Hong YS, Park DW, Choi SH, Moon SW, Park JS, Kim JY and Baek KJ. Lactic acidosis not hyperlactatemia as a predictor of in hospital mortality in septic emergency patients. Emerg Med J. 2008;25:659-65.

4. Gabow PA, Kaehny WD, Fennessey PV, Goodman SI, Gross PA and Schrier RW. Diagnostic importance of an increased serum anion gap. $\mathrm{N}$ Engl J Med. 1980;303:854-8.

5. Kraut JA and Madias NE. Lactic acidosis. N Engl J Med. 2014;371:2309-19.

6. Luft FC. Lactic acidosis update for critical care clinicians. J Am Soc Nephrol. 2001;12 Suppl 17:S15-9.

7. Adeva-Andany M, Lopez-Ojen M, FuncastaCalderon R, Ameneiros-Rodriguez E, DonapetryGarcia C, Vila-Altesor M and Rodriguez-Seijas J. Comprehensive review on lactate metabolism in human health. Mitochondrion. 2014;17:76-100. 
8. Madias NE. Lactic acidosis. Kidney Int. 1986;29:752-74.

9. Cingolani HE, Mattiazzi AR, Blesa ES and Gonzalez NC. Contractility in isolated mammalian heart muscle after acid-base changes. Circ Res. 1970;26:269-78.

10. Fabiato $A$ and Fabiato F. Effects of $\mathrm{pH}$ on the myofilaments and the sarcoplasmic reticulum of skinned cells from cardiace and skeletal muscles. J Physiol. 1978;276:233-55.

11. Solaro RJ, Lee JA, Kentish JC and Allen DG. Effects of acidosis on ventricular muscle from adult and neonatal rats. Circ Res. 1988;63:779-87.

12. Shapiro Jl. Functional and metabolic responses of isolated hearts to acidosis: effects of sodium bicarbonate and Carbicarb. The American journal of physiology. 1990;258:H1835-9.

13. Schotola $H$, Toischer $K$, Popov AF, Renner A, Schmitto JD, Gummert J, Quintel M, Bauer M, Maier LS and Sossalla S. Mild metabolic acidosis impairs the beta-adrenergic response in isolated human failing myocardium. Crit Care. 2012;16:R153.

14. Kimmoun A, Ducrocq N and Levy B. New conclusive data on human myocardial dysfunction induced by acidosis. Crit Care. 2012;16:160.

15. Shapiro Jl. Pathogenesis of cardiac dysfunction during metabolic acidosis: therapeutic implications. Kidney international Supplement. 1997;61:S47-51.

16. Shapiro Jl, Whalen M and Chan L. Hemodynamic and hepatic $\mathrm{pH}$ responses to sodium bicarbonate and Carbicarb during systemic acidosis. Magn Reson Med. 1990;16:403-10.

17. Suleymanlar G, Zhou HZ, McCormack M, Elkins $\mathrm{N}$, Kucera R, Reiss OK and Shapiro Jl. Mechanism of impaired energy metabolism during acidosis: role of oxidative metabolism. The American journal of physiology. 1992;262:H1818-22.

18. Harrison SM, Frampton JE, McCall E, Boyett MR and Orchard $\mathrm{CH}$. Contraction and intracellular $\mathrm{Ca} 2+, \mathrm{Na}+$, and $\mathrm{H}+$ during acidosis in rat ventricular myocytes. The American journal of physiology. 1992;262:C348-57.

19. Choi HS, Trafford AW, Orchard $\mathrm{CH}$ and Eisner DA. The effect of acidosis on systolic Ca2+ and sarcoplasmic reticulum calcium content in isolated rat ventricular myocytes. The Journal of physiology. 2000;529 Pt 3:661-8.
20. Sikes PJ, Zhao P, Maass DL, White J and Horton JW. Sodium/hydrogen exchange activity in sepsis and in sepsis complicated by previous injury: 31P and 23Na NMR study. Crit Care Med. 2005;33:60515.

21. DeSantiago J, Maier LS and Bers DM. Phospholamban is required for CaMKIIdependent recovery of Ca transients and SR Ca reuptake during acidosis in cardiac myocytes. J Mol Cell Cardiol. 2004;36:67-74.

22. Wu LL, Tang C, Dong LW and Liu MS. Altered phospholamban-calcium ATPase interaction in cardiac sarcoplasmic reticulum during the progression of sepsis. Shock. 2002;17:389-93.

23. Dong LW, Wu LL, Ji Y and Liu MS. Impairment of the ryanodine-sensitive calcium release channels in the cardiac sarcoplasmic reticulum and its underlying mechanism during the hypodynamic phase of sepsis. Shock. 2001;16:33-9.

24. Katz AM and Hecht HH. Editorial: the early "pump" failure of the ischemic heart. Am J Med. 1969;47:497-502.

25. Miller RG, Boska MD, Moussavi RS, Carson $\mathrm{PJ}$ and Weiner MW. 31P nuclear magnetic resonance studies of high energy phosphates and $\mathrm{pH}$ in human muscle fatigue. Comparison of aerobic and anaerobic exercise. J Clin Invest. 1988;81:1190-6.

26. Kimmoun A, Novy E, Auchet T, Ducrocq N and Levy B. Hemodynamic consequences of severe lactic acidosis in shock states: from bench to bedside. Crit Care. 2015;19:175.

27. Mitchell JH, Wildenthal K and Johnson RL, Jr. The effects of acid-base disturbances on cardiovascular and pulmonary function. Kidney international. 1972;1:375-89.

28. Darby TD and Watts DT. ACIDOSIS AND BLOOD EPINEPHRINE LEVELS IN HEMORRHAGIC HYPOTENSION. The American journal of physiology. 1964;206:1281-4.

29. Nahas GG, Zagury D, Milhaud A, Manger WM and Pappas GD. Acidemia and catecholamine output of the isolated canine adrenal gland. The American journal of physiology. 1967;213:118692.

30. Nahas GG, Ligou JC and Mehlman B. Effects of $\mathrm{pH}$ changes on oxygen uptake and plasma catecholamine levels in the dog. The American journal of physiology. 1960;198:60-6.

31. Campbell GS. Cardiac arrest: further studies on 
the effect of $\mathrm{pH}$ changes on vagal inhibition of the heart. Surgery. 1955;38:615-34.

32. Cooper DJ, Walley KR, Wiggs BR and Russell JA. Bicarbonate does not improve hemodynamics in critically ill patients who have lactic acidosis. A prospective, controlled clinical study. Annals of internal medicine. 1990;112:492-8.

33. Teplinsky K, O'Toole M, OIman M, Walley KR and Wood LD. Effect of lactic acidosis on canine hemodynamics and left ventricular function. The American journal of physiology. 1990;258:H11939.

34. Davies AO. Rapid desensitization and uncoupling of human beta-adrenergic receptors in an in vitro model of lactic acidosis. J Clin Endocrinol Metab. 1984;59:398-405.

35. Kellum JA, Song M and Venkataraman R. Effects of hyperchloremic acidosis on arterial pressure and circulating inflammatory molecules in experimental sepsis. Chest. 2004;125:243-8.

36. Orchard $\mathrm{CH}$ and Cingolani HE. Acidosis and arrhythmias in cardiac muscle. Cardiovasc Res. 1994;28:1312-9.

37. Arieff Al, Leach W, Park R and Lazarowitz VC. Systemic effects of $\mathrm{NaHCO} 3$ in experimental lactic acidosis in dogs. The American journal of physiology. 1982;242:F586-91.

38. Graf H, Leach W and Arieff Al. Evidence for a detrimental effect of bicarbonate therapy in hypoxic lactic acidosis. Science. 1985;227:754-6.

39. Adler S, Roy A and Relman AS. Intracellular Acid-Base Regulation. I. The Response of Muscle Cells to Changes in Co2 Tension or Extracellular Bicarbonate Concentration. J Clin Invest. 1965;44:8-20.

40. Kraut JA and Madias NE. Treatment of acute metabolic acidosis: a pathophysiologic approach. Nat Rev Nephrol. 2012;8:589-601.

41. Shapiro Jl, Whalen M, Kucera R, Kindig N, Filley $\mathrm{G}$ and Chan L. Brain pH responses to sodium bicarbonate and Carbicarb during systemic acidosis. The American journal of physiology. 1989;256:H1316-21.

42. Kindig NB, Sherrill DS, Shapiro JI and Filley GF. Extracorporeal bicarbonate space after bicarbonate or a bicarbonate-carbonate mixture in acidotic dogs. J Appl Physiol (1985). 1989;67:2331-4.

43. Shapiro Jl, Mathew A, Whalen M, Honigman B, Kaehny WD, Petty TL and Chan L. Different effects of sodium bicarbonate and an alternate buffer (Carbicarb) in normal volunteers. Journal of Critical Care. 1990;5:157-160.

44. Olson DE, Dart GA and Filley GF. Pressure drop and fluid flow regime of air inspired into the human lung. J Appl Physiol. 1970;28:482-94.

45. Shapiro Jl, Elkins N, Logan J, Ferstenberg LB and Repine JE. Effects of sodium bicarbonate, disodium carbonate, and a sodium bicarbonate/ carbonate mixture on the PCO2 of blood in a closed system. J Lab Clin Med. 1995;126:65-9.

46. Kimmoun A, Ducrocq N, Sennoun N, Issa K, Strub C, Escanye JM, Leclerc S and Levy B. Efficient extra- and intracellular alkalinization improves cardiovascular functions in severe lactic acidosis induced by hemorrhagic shock. Anesthesiology. 2014;120:926-34.

47. Allegretti AS, Flythe JE, Benda V, Robinson ES and Charytan DM. The effect of bicarbonate administration via continuous venovenous hemofiltration on acid-base parameters in ventilated patients. BioMed research international. 2015;2015:901590.

48. Rocktaschel J, Morimatsu H, Uchino S, Ronco $C$ and Bellomo R. Impact of continuous venovenous hemofiltration on acid-base balance. Int J Artif Organs. 2003;26:19-25.

49. Nahas GG, Sutin KM, Fermon C, Streat S, Wiklund $L$, Wahlander $S$, Yellin $P$, Brasch $H$, Kanchuger $M$, Capan L, Manne J, Helwig H, Gaab M, Pfenninger $\mathrm{E}$, Wetterberg $\mathrm{T}$, Holmdahl $\mathrm{M}$ and Turndorf $\mathrm{H}$. Guidelines for the treatment of acidaemia with THAM. Drugs. 1998;55:191-224.

50. Moon PF, Gabor L, Gleed RD and Erb HN. Acidbase, metabolic, and hemodynamic effects of sodium bicarbonate or tromethamine administration in anesthetized dogs with experimentally induced metabolic acidosis. American journal of veterinary research. 1997;58:771-6.

51. Wildenthal K, Mierzwiak DS, Myers RW and Mitchell JH. Effects of acute lactic acidosis on left ventricular performance. The American journal of physiology. 1968;214:1352-9.

52. Sirieix D, Delayance $S$, Paris $M$, Massonnet-Castel S, Carpentier A and Baron JF. Tris-hydroxymethyl aminomethane and sodium bicarbonate to buffer metabolic acidosis in an isolated heart model. American journal of respiratory and critical care medicine. 1997;155:957-63. 
53. Hoste EA, Colpaert K, Vanholder RC, Lameire NH, De Waele JJ, Blot SI and Colardyn FA. Sodium bicarbonate versus THAM in ICU patients with mild metabolic acidosis. Journal of nephrology. 2005; 18:303-7.

54. Stacpoole PW. The pharmacology of dichloroacetate. Metabolism: clinical and experimental. 1989;38:1124-44.

55. Wilkerson DP, Campbell IT, Blackwell JR, Berger $\mathrm{NJ}$ and Jones AM. Influence of dichloroacetate on pulmonary gas exchange and ventilation during incremental exercise in healthy humans. Respiratory physiology \& neurobiology. 2009;168:224-9.

56. Stacpoole PW, Wright EC, Baumgartner TG, Bersin RM, Buchalter S, Curry SH, Duncan CA, Harman EM, Henderson GN, Jenkinson $S$ and et al. A controlled clinical trial of dichloroacetate for treatment of lactic acidosis in adults. The Dichloroacetate-Lactic Acidosis Study Group. N Engl J Med. 1992;327:1564-9.

57. Filley GF and Kindig NB. Carbicarb, an alkalinizing ion-generating agent of possible clinical usefulness. Trans Am Clin Climatol Assoc. 1985;96:141-53.

58. Li YC, Wiklund L and Bjerneroth G. Influence of alkaline buffers on cytoplasmic $\mathrm{pH}$ in myocardial cells exposed to hypoxia. Resuscitation. 1997;34:71-7.

59. Li YC, Wiklund L, Tarkkila P and Bjerneroth G. Influence of alkaline buffers on cytoplasmic $\mathrm{pH}$ in myocardial cells exposed to metabolic acidosis. Resuscitation. 1996;32:33-44.

60. Bersin RM and Arieff Al. Improved hemodynamic function during hypoxia with Carbicarb, a new agent for the management of acidosis. Circulation. 1988;77:227-33.

61. Leung JM, Landow L, Franks M, Soja-Strzepa D, Heard SO, Arieff Al and Mangano DT. Safety and efficacy of intravenous Carbicarb in patients undergoing surgery: comparison with sodium bicarbonate in the treatment of mild metabolic acidosis. SPI Research Group. Study of Perioperative Ischemia. Critical care medicine. 1994;22:1540-9.

62. Kolloffel WJ, de Vroom TE, Weekers LE and Woittiez AJ. Severe cutaneous side effects of peripheral infusions with carbicarb half strength. Intensive Care Med. 1994;20:531. 
